\title{
SISTEM INFORMASI PENGELOLAAN HOTEL DI KOTA PADANG MENGGUNAKAN MAPBOX GRAPHIC LIBRARY BERBASIS FRAMEWORK CODEIGNITER
}

\author{
Taufik Dirwanto ${ }^{1}$ \\ Asrul Huda ${ }^{2}$ \\ Ahmaddul Hadi ${ }^{3}$
}

\begin{abstract}
Hospitality is a vital tool serving local and international tourists in Padang City. The problem arises when the limited information of hospitality makes it difficult for travelers who want to book a hotel. The design of hotel management information system in Padang City aims to produce a web-based information system that can provide hotel information so as to facilitate tourists in finding hotels. The development of information technology includes Management Information System (MIS). The use of Mapbox digital map to build a Management Information System (MIS) becomes one of the effective means for promotion media and hotel information in Padang city. The design of hotel management information system in Padang City using UML modeling visualization (Unified Modeling Language) with object oriented visualization diagram. System development method using Prototype model. The programming language used is the PHP programming language (PHP Hypertext Preprocessor) based on codeigniter framework and Javascript, AJAX, with MySQL as Database Management System (DBMS), and Sublime Text 3 as editor. The design of information systems display information about the location of the hotel along with tracking service or direction using GPS, room type, price, facilities, rating, and reviews available.
\end{abstract}

Keywords: Management Information System, Mapbox, UML

\footnotetext{
${ }^{1}$ Mahasiswa Prodi Pendidikan Teknik Informatika, Author

2. Dosen Universitas Negeri Padang

3. Dosen Universitas Negeri Padang
} 


\section{INTI SAR I}

Perhotelan merupakan alat vital yang melayani wisatawan lokal dan internasional di Kota Padang. Masalah muncul ketika informasi terbatas dari keramahan membuat sulit bagi wisatawan yang ingin memesan hotel. Perancangan sistem informasi manajemen hotel di Kota Padang bertujuan untuk menghasilkan sistem informasi berbasis web yang dapat memberikan informasi hotel sehingga memudahkan wisatawan dalam mencari hotel. Perkembangan teknologi informasi termasuk Sistem Informasi Manajemen (SIM). Penggunaan peta digital Mapbox untuk membangun Sistem Informasi Manajemen (SIM) menjadi salah satu sarana efektif untuk media promosi dan informasi hotel di kota Padang. Perancangan sistem informasi manajemen hotel di Kota Padang menggunakan visualisasi model UML (Unified Modeling Language) dengan diagram visualisasi berorientasi objek. Metode pengembangan sistem menggunakan model Prototype. Bahasa pemrograman yang digunakan adalah bahasa pemrograman PHP (PHP Hypertext Preprocessor) berdasarkan framework codeigniter dan Javascript, AJAX, dengan MySQL sebagai Database Management System (DBMS), dan Sublime Text 3 sebagai editor. Perancangan sistem informasi menampilkan informasi tentang lokasi hotel bersama dengan layanan pelacakan atau arah menggunakan GPS, jenis kamar, harga, fasilitas, rating, dan ulasan yang tersedia.

Kata Kunci : Sistem Informasi Manajemen, Mapbox, UML 


\section{PENDAHULUAN}

\begin{tabular}{lrr}
\multicolumn{2}{r}{ Berdasarkan } & \multicolumn{2}{r}{ Keputusan } \\
Menteri Pariwisata dan & $\begin{array}{r}\text { Ekonomi } \\
\text { Kreatif }\end{array}$ \\
PM.53/HM.001/MPEK/2013 & tentang
\end{tabular}

Standar Usaha Hotel, dijelaskan dalam Pasal 1 ayat 4 bahwa Usaha Hotel adalah usaha penyediaan akomodasi berupa kamar-kamar di dalam suatu bangunan, yang dapat dilengkapi dengan jasa pelayanan makan dan minum, kegiatan hiburan dan/atau fasilitas lainnya secara harian dengan tujuan memperoleh keuntungan.

Hotel termasuk sarana pokok kepariwisataan (main tourism superstructure). Fungsi utama hotel sebagai sarana akomodasi tempat menginap sementara bagi para tamu yang datang dari berbagai tempat. Namun seiring perkembangan zaman fungsi hotel tidak hanya sebagai tempat menginap saja, akan tetapi sekarang ini fungsi hotel juga sebagai tempat melakukan pertemuan bisnis, seminar, tempat berlangsungnya pesta pernikahan (resepsi), lokakarya, musyawarah nasional dan kegiatan lainnya. Sistem Informasi Manajemen (SIM) merupakan sistem informasi yang digunakan oleh suatu organisasi maupun perusahaan untuk mengelola semua transaksi yang mendukung fungsi manajemen. Sistem informasi manajemen tersebut akan memudahkan semua pihak untuk memperoleh informasi berupa data perhotelan yang dapat diakses melalui perangkat komputer atau smartphone. Salah satunya untuk mendapatkan informasi perhotelan Kota Padang. Kota Padang merupakan ibukota provinsi dan salah satu kota wisata yang ada di Sumatera Barat dengan jumlah hotel yang selalu meningkat. Perkembangan jumlah hotel di Kota Padang disajikan sebagai berikut:
Tabel 1. Jumlah hotel Kota Padang tiap tahunnya.

\begin{tabular}{|c|c|c|}
\hline No & Tahun & Jumlah Hotel \\
\hline 1 & 2013 & 82 \\
\hline 2 & 2014 & 90 \\
\hline 3 & 2015 & 94 \\
\hline
\end{tabular}

Berdasarkan data tersebut dapat disimpulkan bahwa hotel di Kota Padang mengalami pertumbuhan dalam 3 tahun terakhir. Pada tahun 2015 terdapat 94 hotel di Kota Padang yang terdiri dari 33 hotel berbintang dan 61 hotel non bintang.

Tabel 2. Jenis Hotel di Kota Padang pada tahun 2015

\begin{tabular}{|c|c|c|}
\hline No & Jenis Hotel & Jumlah \\
\hline 1 & Bintang 5 & 1 \\
\hline 2 & Bintang 4 & 7 \\
\hline 3 & Bintang 3 & 10 \\
\hline 4 & Bintang 2 & 8 \\
\hline 5 & Bintang 1 & 3 \\
\hline 6 & Syariah Hilal 1 & 48 \\
\hline 7 & Melati & 3 \\
\hline 8 & Homestay & 7 \\
\hline 9 & Lainnya & $\mathbf{9 4}$ \\
\hline
\end{tabular}

Sumber : BPS Sumatera Barat; Direktorat Hotel dan Akomodasi lainnya Sumatera barat 2015 .

Informasi akurat yang didapatkan oleh wisatawan didapatkan dari pengelola hotel karena pengelola lah yang mengetahui situasi dan kondisi serta fasilitas yang ada di hotel yang dikelolanya. Untuk memberikan informasi yang akurat tersebut, pengelola harus mengiklankan hotelnya dan membutuhkan media iklan atau promosi. Namun saat ini pengelola hotel yang mengiklankan hotelnya sangat terbatas. Jadi, informasi yang didapatkan dari media tersebut tidak lengkap sehingga pencari hotel harus mencari hotel secara manual.

Terkait berbagai macam kelemahan tersebut akan menyulitkan wisatawan menemukan hotel yang ada di Kota Padang. Berdasarkan kelemahan-kelemahan yang dimilikinya tersebut, cara ini dinilai kurang efektif dan kurang efisien. Untuk mengatasi kelemahan- 
kelemahan tersebut, maka saat ini dengan perkembangan teknologi informasi yang dimiliki, penulis dapat menggunakan peta digital Mapbox Graphic Library untuk membangun sistem informasi manajemen yang menampilkan lokasi hotel yang ada di Kota Padang. Mapbox Graphic Library dapat digunakan oleh pihak lain untuk dimanfaatkan dan dikembangkan.

Sistem informasi yang memanfaatkan peta digital Mapbox Graphic Library ini akan memudahkan para wisatawan untuk mencari hotel yang terdapat di Kota Padang. Sistem informasi lokasi hotel ini dibangun menggunakan framework Codeigniter yang berbasis OOP (Object Oriented Progrming).

Seringkali penyebab sulitnya mengetahui informasi perhotelan disebabkan karena media promosi dan informasi yang terbatas mengenai jumlah, harga, fasilitas, dan alamat hotel yang berada di Kota Padang.

Sistem informasi adalah solusi
untuk mengatasi keterbatasan
informasi mengenai perhotelan di
Kota Padang. Sistem yang dibutuhkan dapat diakses oleh pengunjung dimanapun dan kapanpun untuk mencari dan memesan hotel yang tersedia di Kota Padang. Sistem informasi memberikan kemudahan kepada pengelola hotel untuk mengiklankan hotel yang ada di Kota Padang, khususnya Padang Barat. Sistem juga melayani pemesanan kamar hotel dan memberikan notifikasi melalui e-mail.

Sistem ini menggunakan teknologi framework Codeigniter versi 2.2.0 dengan menggunakan bahasa pemrograman PHP (PHP Hypertext Preprocessor) berbasis framework, MySQL sebagai Databese Management System (DBMS), Javascript, AJAX, XAMPP dan Sublime Text 3 editor.
Adapun maksud dan tujuan dari pengembangan sistem ini adalah: 1) Membangun sistem informasi pengelolaan hotel di Kota Padang menggunakan Mapbox Graphic Library berbasis web menggunakan framework Codeigniter, 2) Membangun sebuah sistem informasi yang memberi kemudahan bagi pencari hotel, 3) Membangun sistem informasi yang mempermudah pihak perhotelan dalam melakukan pengelolaan proses manajemen.

\section{PENDEKATAN MASALAH}

\section{Analisis \& Perancangan Sistem}

\section{Analisis Sistem}

Analisis sistem adalah penguraian dari suatu sistem yang utuh ke dalam bagianbagian komponennya dengan maksud untuk mengidentifikasi dan mengevaluasi permasalahan. Analisis sistem terdiri dari dua komponen yaitu analisis yang sedang berjalan dan analisis yang diusulkan. Beberapa komponen analisis sistem sebagai berikut:

a. Analisis yang sedang berjalan

$$
\begin{aligned}
& \text { Analisis sistem yang } \\
& \text { berjalan } \\
& \text { bagaimana menjelaskan } \\
& \text { terhadap sistem gambaran } \\
& \text { berjalan saat ini, yang } \\
& \text { meliputi yang } \\
& \text { Analisis proses bisnis, } \\
& \text { analisis aturan bisnis, } \\
& \text { analisis pelaku, analisis } \\
& \text { masalah dan solusi, serta } \\
& \text { flow-map yang sedang } \\
& \text { berjalan saat ini. }
\end{aligned}
$$

b. Analisis yang diusulkan
$\begin{array}{lrr}\text { Analisis } & \text { sistem yang } \\ \text { diusulkan } & \text { menjelaskan } \\ \text { gambaran } & \text { terhadap sistem }\end{array}$
yang akan diusulkan untuk dikembangkan
guna
menyelesaikan
permasalahan yang sedang berjalan saat ini, yang 
meliputi diantaranya:

Analisis User, yang terdiri dari user server dan client; Analisis Proses dan Prosedur; Analisis dokumen $\mathrm{I} / \mathrm{O}$, yang terdiri dari dokumen I/O pada server dan client; Analisis persyaratan fungsional dan non-fungsional; serta flowmap yang akan diusulkan.

\section{Perancangan Sistem}

Perancangan sistem secara keseluruhan pada sistem informasi ini mengacu kepada panduan yang terdapat pada buku Rosa A. S \& $M$. Shalahuddin (2013) tentang rekayasa perangkat lunak. Perancangan sistem dilakukan untuk menggambarkan dan merencanakan, dari beberapa elemen yang terpisah ke dalam satu kesatuan yang utuh. Beberapa komponen analisis sistem diantaranya:

a. Context Diagram

Context Diagram merupakan tingkatan tertinggi dalam diagram alur data dan menunjukan sistem secara keseluruhan serta menggambarkan secara jelas mengenai ruang lingkup masukan dan keluaran dari sistem yang dikembangkan. Berdasarkan analisis user, berkut ini adalah perancangan context diagram pada server dan client.

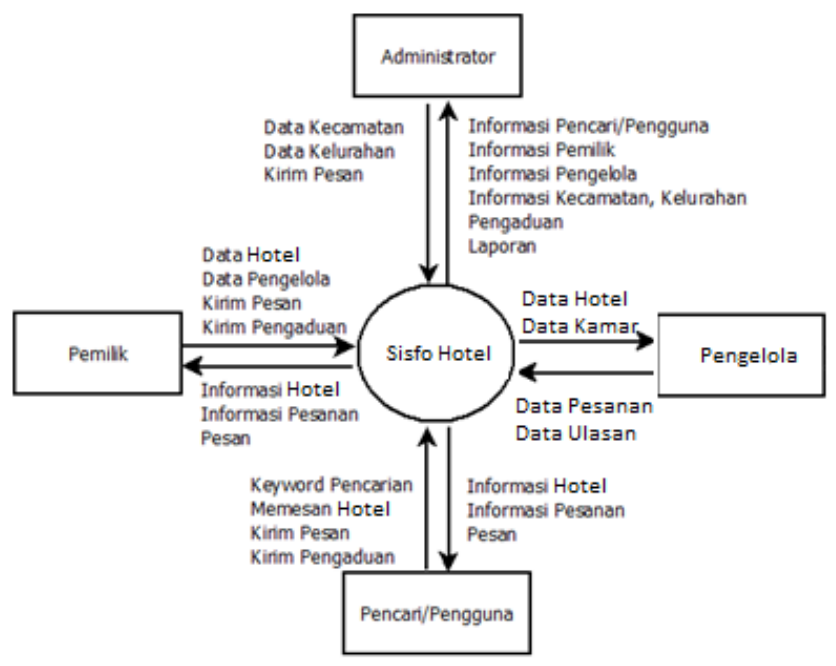

Gambar 1. Rancangan Diagram Konteks

b. Use Case Diagram

Use Case diagram merupakan gambaran skenario dari interaksi yang menggambarkan hubungan antara aktor dan kegiatan yang dapat dilakukannya terhadap aplikasi. Aplikasi ini melibatkan 3 aktor yaitu Admin, Pengelola, dan member. Terdapat dua bagian use case diagram yang dirancang untuk sistem yaitu perancangan use case server dan client. Berikut ini adalah gambar perancangan use case diagram:

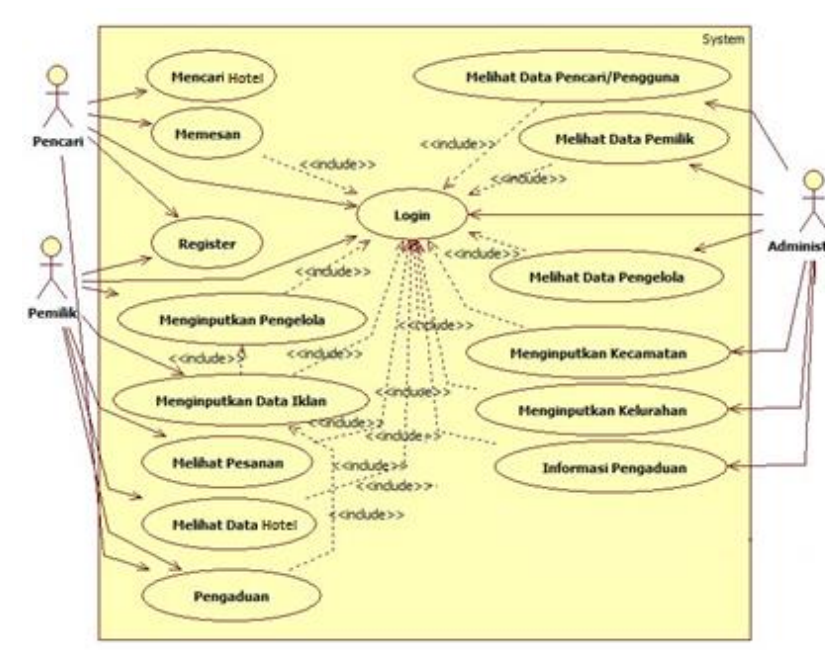

Gambar 2. Rancangan Diagram Use-case 
c. Activity Diagram

Activity memodelkan

diagram proses bisnis dan urutan aktivitas dalam sebuah proses. Diagram ini sangat mirip dengan flowchart karena memodelkan workflow dari satu aktivitas ke aktivitas lainnya. Berikut adalah diagram aktivitas dari sistem informasi pengelolaan lokasi hotel di Kota Padang:

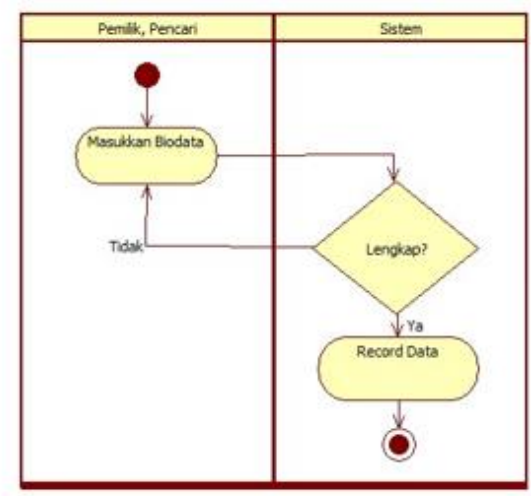

Gambar 3. Activity Diagram Registrasi Pengguna

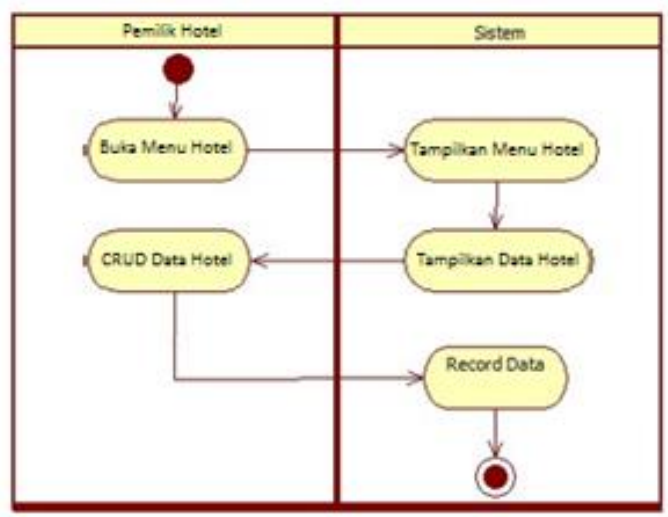

Gambar 4. Activity Diagram CRUD Data Hotel

d. Sequence Diagram

Sequence

digunakan

diagram

untuk

menggambarkan

proses

yang dilakukan oleh pengguna (user) terhadap sistem. Pada sistem ini terdapat beberapa sequence diagram pada server dan client, diantaranya sebagai berikut:

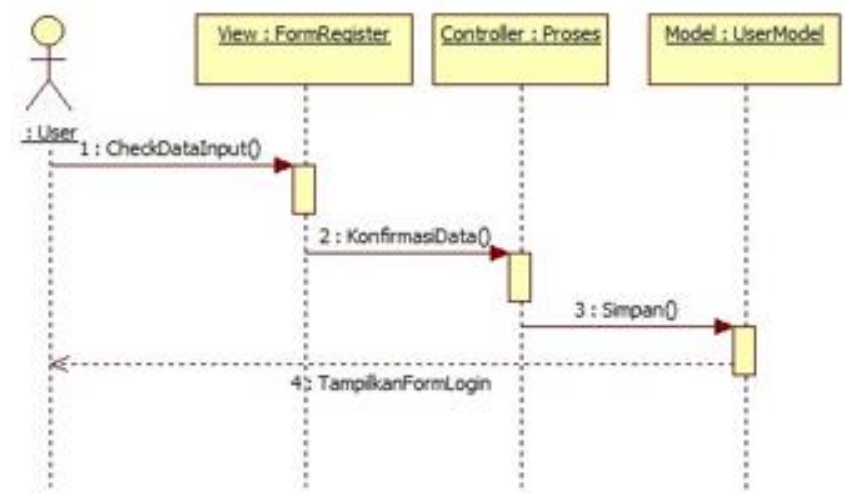

Gambar 5. Sequence Diagram Registrasi

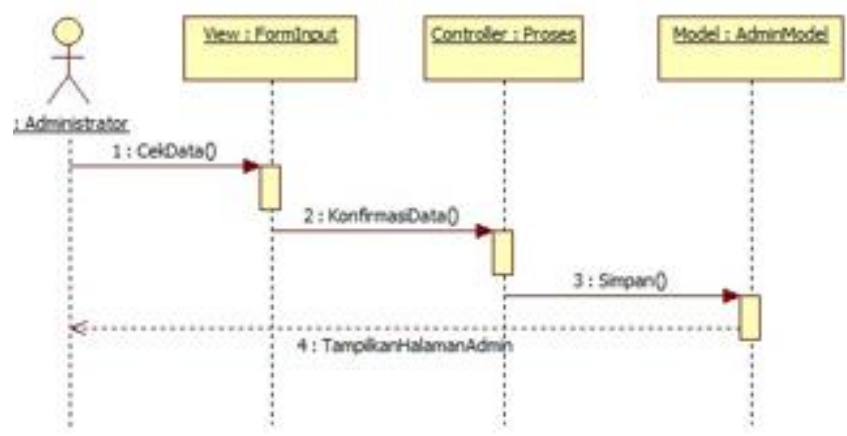

Gambar 6. Sequence Diagram Administrator

e. Class Diagram

Kelas (Class) adalah sebuah spesifikasi yang jika diinstansiasi akan menghasilkan sebuah objek dan merupakan inti dari pengembangan dan perancangan berorientasi objek. Kelas menggambarkan keadaan (atribut/ properti) suatu sistem, sekaligus menawarkan layanan untuk memanipulasi keadaan tersebut (metode/fungsi). 


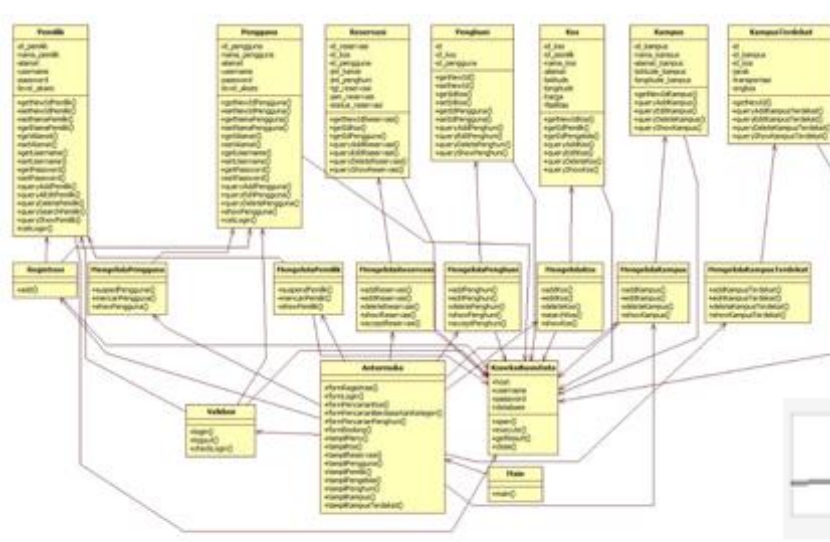

Gambar 7. Class Diagram Sisfo Hotel

\section{f. Perancangan Keamanan}

Sistem yang memiliki data atau transaksi yang bersifat rahasia harus memiliki keamanan yang baik. Keamanan yang baik untuk sistem informasi menggunakan berbagai macam metode atau teknik keamanan.

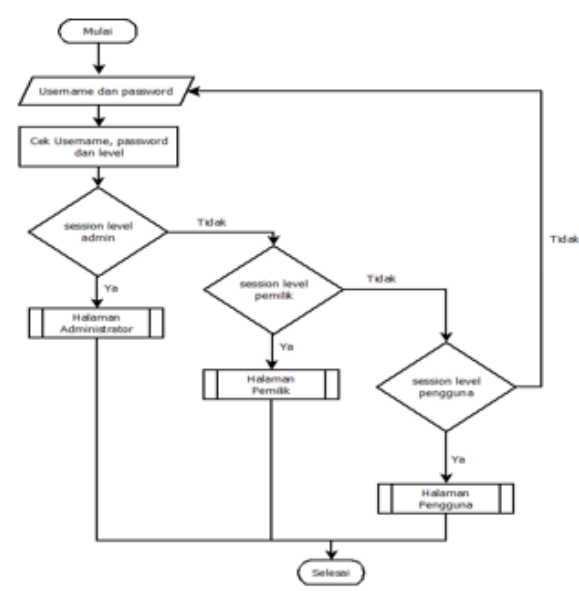

Gambar 8. Teknik Keamanan Session

Perancangan teknik enkripsi data yang digunakan adalah teknik enkripsi MD5. Enkripsi MD5 dapat dilihat seperti gambar berikut :

Kata

Enkripsi MD5
: admin

: 21232f297a57a5a743894a0e4a801fc3

Gambar 9. Enkripsi MD5
Perancangan keamanan menggunakan captcha. Captcha merupakan teknik keamanan yang menggunakan metode pengacakan angka, huruf dan angka dan huruf. Berikut ini adalah perancangannya:

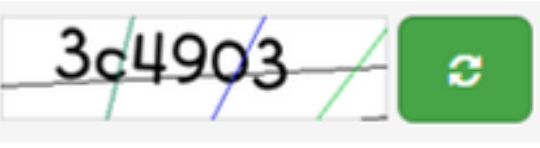

Gambar 10. Captcha

3. Perancangan Basis Data

Perancangan basis data merupakan upaya untuk membangun sebuah basis data dalam suatu lingkungan bisnis. Perancangan basis data dilakukan agar tidak terjadi redudansi data, duplikasi data dan inkonsistensi data. Untuk membangunnya terdapat tahapan-tahapan seperti normalisasi, perancangan struktur tabel dan perancangan entity relationship diagram (ERD). Berikut ini adalah gambar perancangan ERD:

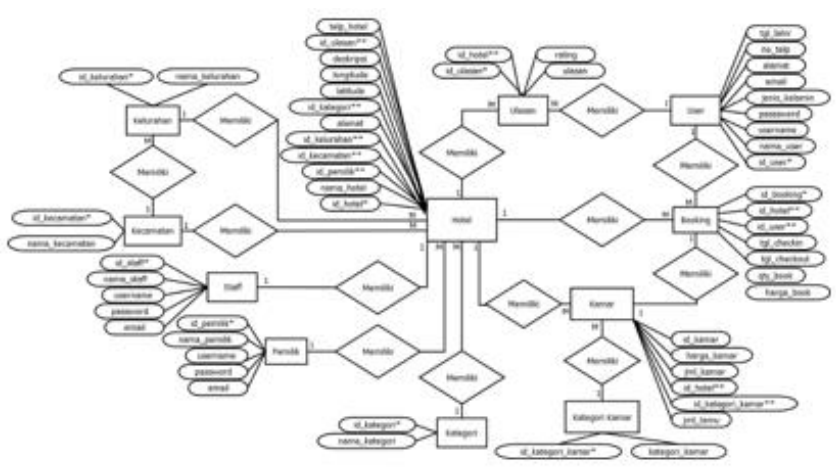

Gambar 11. Rancangan ERD

4. Perancangan Interface

Perancangan antarmuka ini bertujuan untuk merencanakan antarmuka yang akan digunakan pada sistem yang akan dibangun. Perencanaan antarmuka (tampilan) harus bersifat nyaman 
dilihat, mudah digunakan, tidak ambigu dan lain sebagainya. Perancangan interface dibagi menjadi beberapa bagian rancangan interface.

a. Desain Halaman Utama

Tampilan halaman utama merupakan tampilan yang akan muncul pertama kali pada saat membuka alamat halaman web. Perancangan antarmuka halaman utama ditampilkan dengan menggunakan query SQL sebagai berikut :

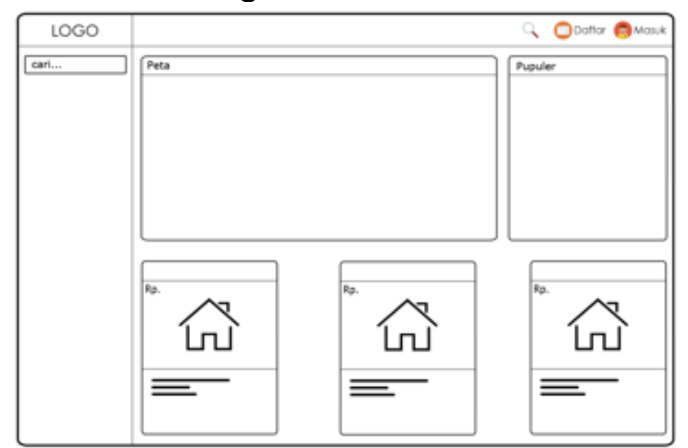

Gambar 12. Rancangan Interface Halaman Utama

b. Desain Halaman Registrasi Halaman registrasi merupakan halaman yang disediakan untuk melakukan pendaftaran agar pengguna bisa mengakses sesuai fungsi dan hak akses mereka masing-masing. Berikut adalah rancangan interface halaman register:

\begin{tabular}{|l|l|}
\hline Lo60 & \\
\hline & Registrasi \\
\hline Nama & \\
\hline & Jenis Kelamin \\
Alamat & \\
E-mail & \\
Telepon & \\
Password & \\
& \\
\hline
\end{tabular}

Gambar 13. Rancangan Interface Halaman Registrasi c. Desain Tampilan Login

Rancangan tampilan login merupakan tampilan yang akan digunakan sebagai gerbang untuk mengakses sistem secara luas. Berikut rancangan login tersebut:

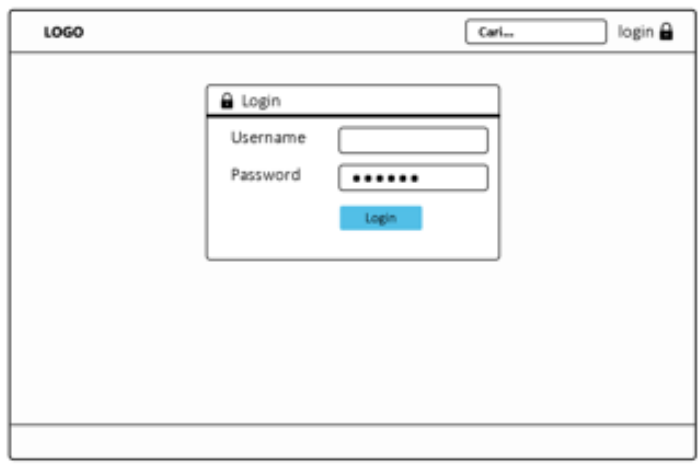

Gambar 14. Rancangan Interface Login

d. Desain Tampilan Input Data Rancangan tampilan inputan data merupakan tampilan yang digunakan untuk menginputkan data hotel berupa nama hotel, alamat, fasilitas, harga dan lain sebagainya ke dalam basis data. Berikut model rancangan inputan:

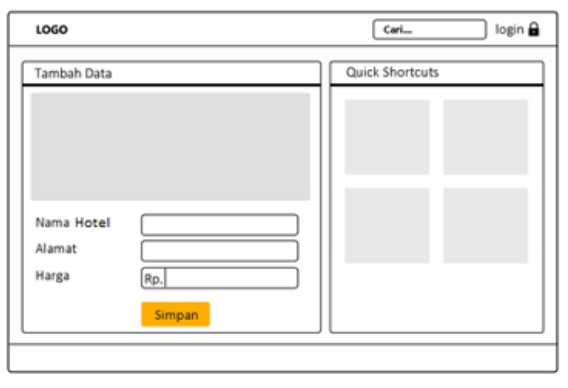

Gambar 15. Rancangan Interface Input Data

e. Desain Tampilan Data

Tampilan data hotel dibuat dalam bentuk tabel, agar data ditampilkan secara terstruktur. Pada tampilan data tersebut disediakan tombol untuk melakukan proses perubahan data dan tombol untuk menghapus. 


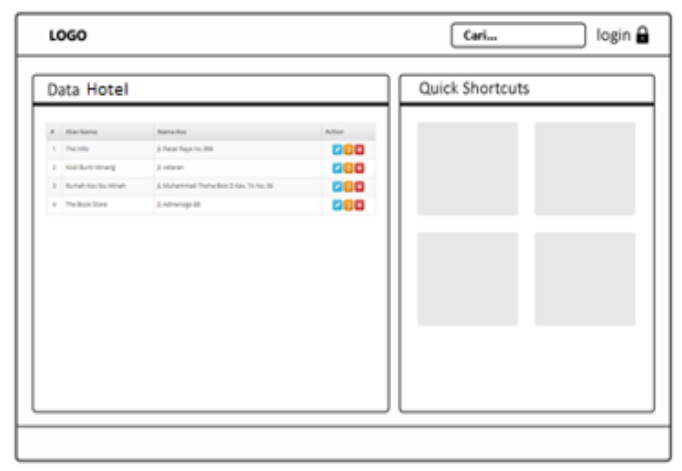

Gambar 16. Rancangan Interface Halaman Tampilan Data

f. Tampilan Lokasi

Data lokasi hotel yang tersedia ditampilkan dengan menggunakan peta digital (Mapbox Graphic Library). Posisi masing-masing hotel ditentukan menggunakan penanda (markers). Penanda antara kategori hotel berbintang dan tidak dibedakan, agar tidak menyulitkan pengguna menggunakan sistem ini. Tampilannya dapat dilihat seperti gambar berikut:

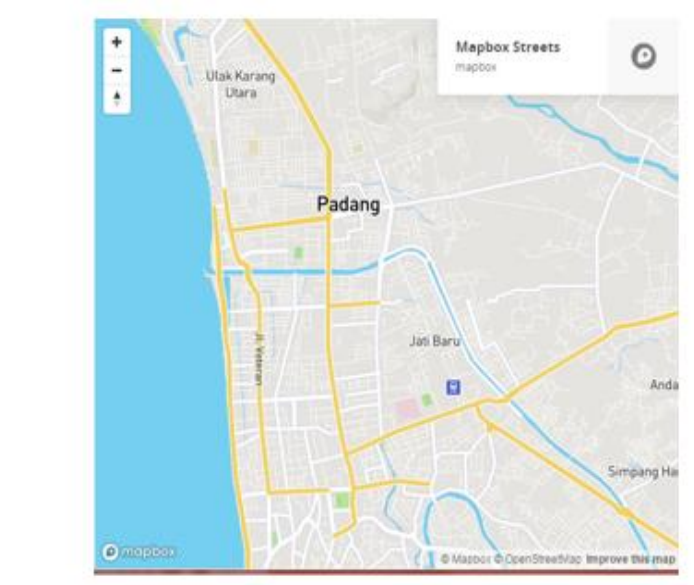

Gambar 17. Rancangan Interface Lokasi Menggunakan Mapbox

\section{HASIL DAN PEMBAHASAN}

Hasil antarmuka adalah hasil dari menerjemahkan layout yang sudah dibuat sebelumnya pada desain antarmuka ke dalam bentuk tampilan antarmuka sistem secara utuh. Hasil antarmuka sistem ini dilakukan untuk mengetahui apakah sistem yang telah dirancang dapat berjalan dengan benar sesuai dengan perancangan yang telah dirancang sebelumnya.

1. Interface pada User

Halaman ini merupakan halaman yang bisa diakses oleh setiap user ketika membuka halaman website sistem informasi pengelolaan hotel di Kota Padang.

a. Halaman Utama

Halaman

utama merupakan halaman yang digunakan bagi user yang telah terdaftar pada sistem untuk masuk dan memanfaatkan menu-menu di dalam sistem.

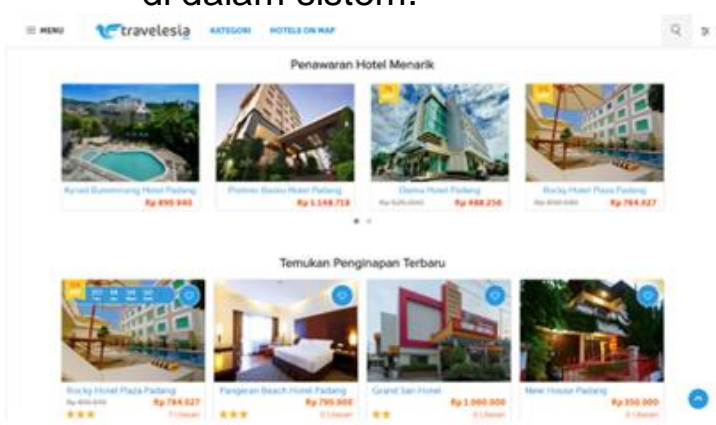

Gambar 18. Tampilan Halaman Utama

b. Halaman Registrasi

Halaman registrasi digunakan oleh setiap user untuk mendaftarkan akun agar mendapatkan username dan password. Halaman registrasi ditunjukan seperti gambar di bawah ini.

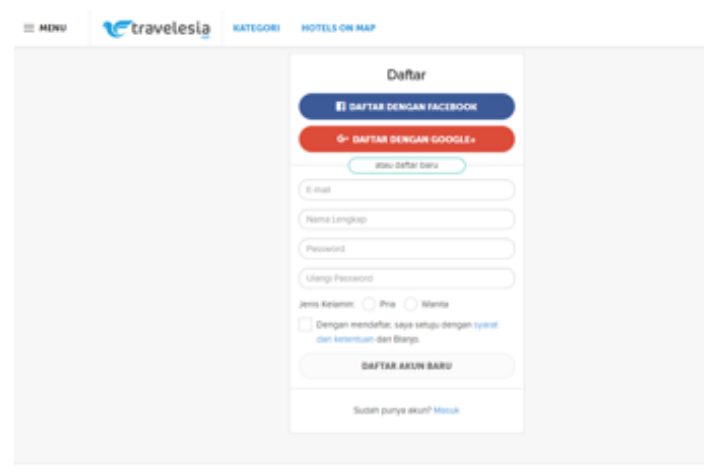

Gambar 19. Tampilan Halaman Registrasi 
c. Halaman Live Maps

Halaman pencarian ini digunakan untuk mencari hotel lebih cepat.

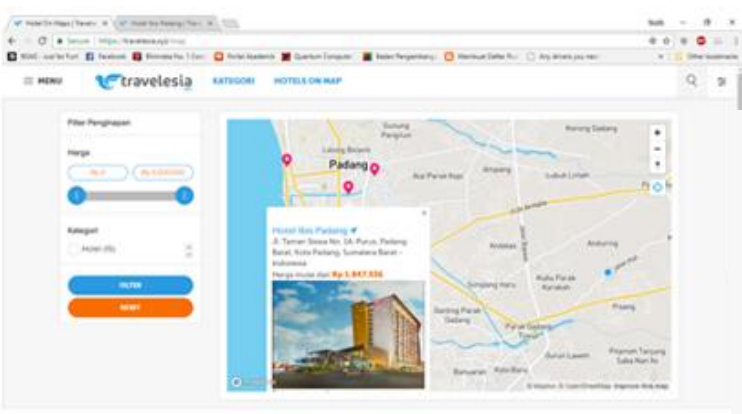

Gambar 20. Tampilan Halaman Live Maps

d. Halaman Detail Hotel Halaman detail hotel ini berfungsi untuk melihat apa saja fasilitas yang ada dihotel tersebut. Adapun tampilan halaman hotel sebagai berikut :

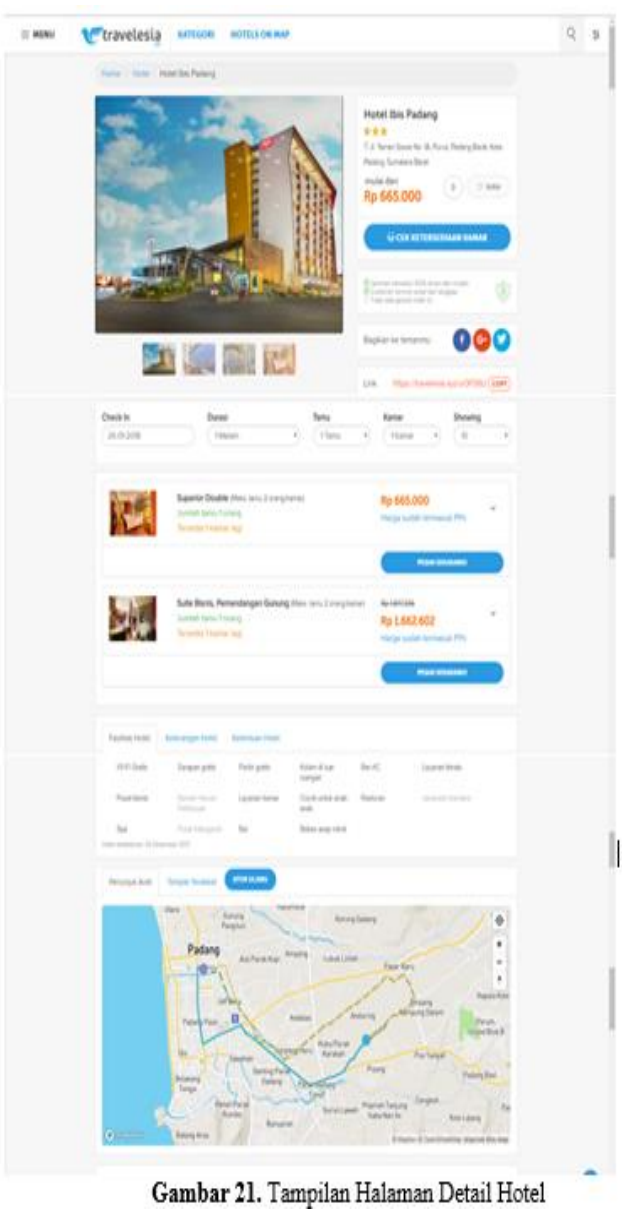

e. Halaman Booking Halaman pemesanan atau booking dilakukan dengan memilih tanggal menginap, jumlah kamar, jumlah tamu, kemudian pilih jenis kamar.

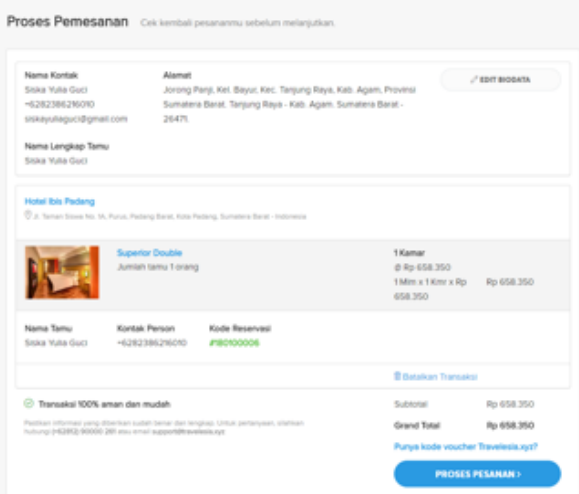

Gambar 22. Tampilan Halaman Booking

f. Halaman Pembayaran

Halaman pembayaran menampilkan metode pembayaran yang dapat dilakukan untuk melanjutkan proses pemesanan kamar hotel.

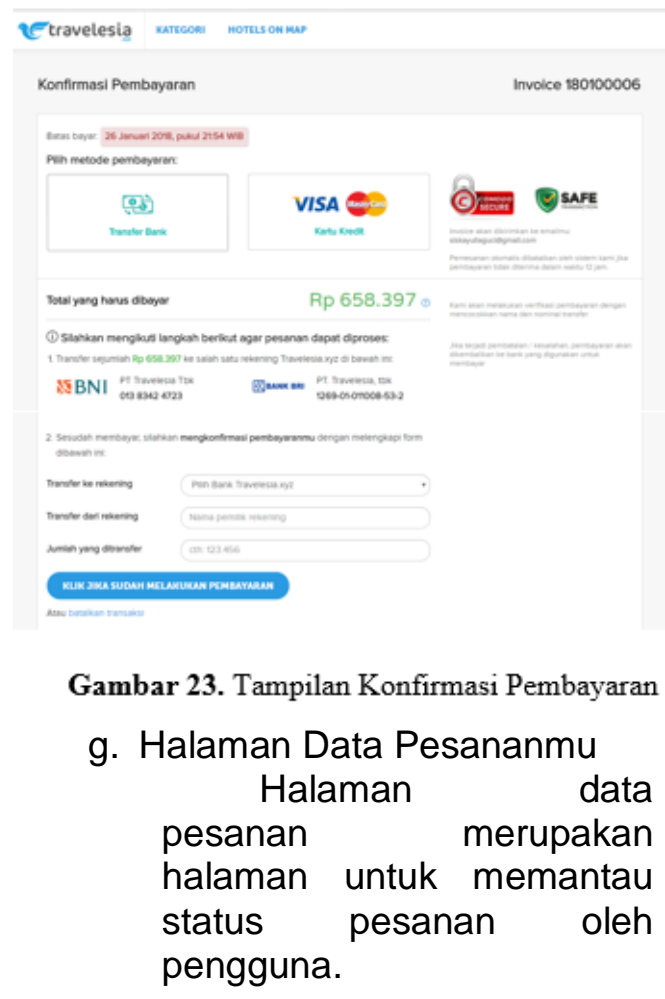




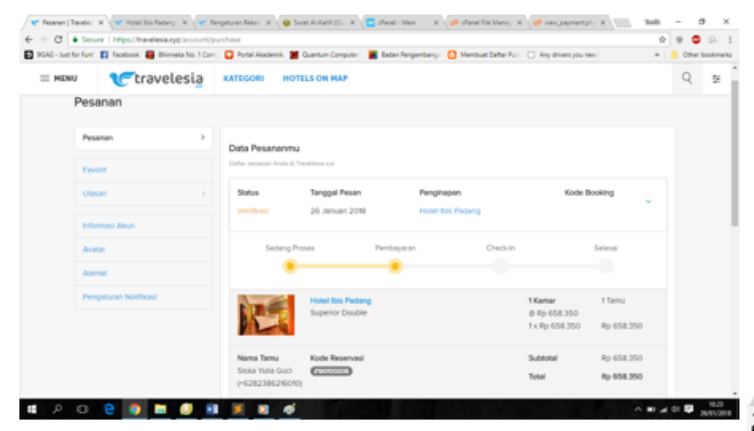

Gambar 24. Data Pesananmu

Kode booking akan muncul setelah pembayaran diverifikasi.

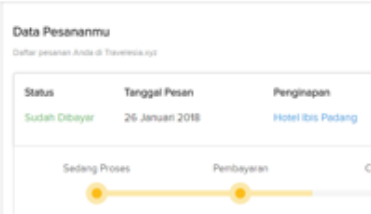

Gambar 25. Kode Booking

\section{Interface pada Admin}

Halaman Admin adalah merupakan pengendali dari sebuah sistem dalam menjalankan prosedur tertentu. Halaman admin adalah tempat dimana admin dapat mengatur, mengontrol dan memanajemen proses yang ada pada suatu.

1. Dashboard Admin

Dashboard admin merupakan tampilan layar untuk admin melakukan proses pengelolaan sistem secara keseluruhan.

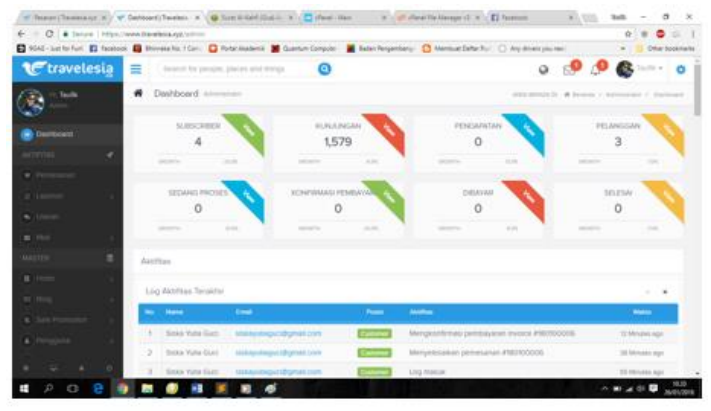

Gambar 26. Halaman Admin
2. Halaman Tambah Hotel

Halaman tambah hotel merupakan halaman untuk melakukan penambahan hotel ke dalam database. Berikut adalah halaman menu tambah hotel pada dashboard admin:
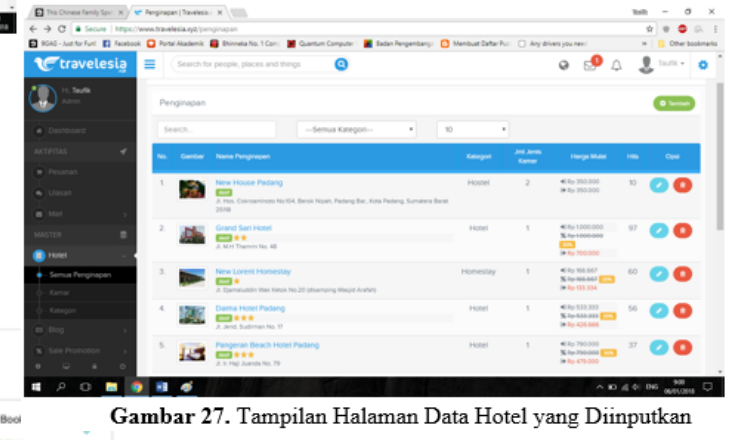

\section{Halaman Edit Hotel}

Halaman edit merupakan halaman yang digunakan oleh pengelola hotel untuk merubah data yang telah diinputkan. Tampilan halaman edit hotel dapat dilihat sebagai berikut

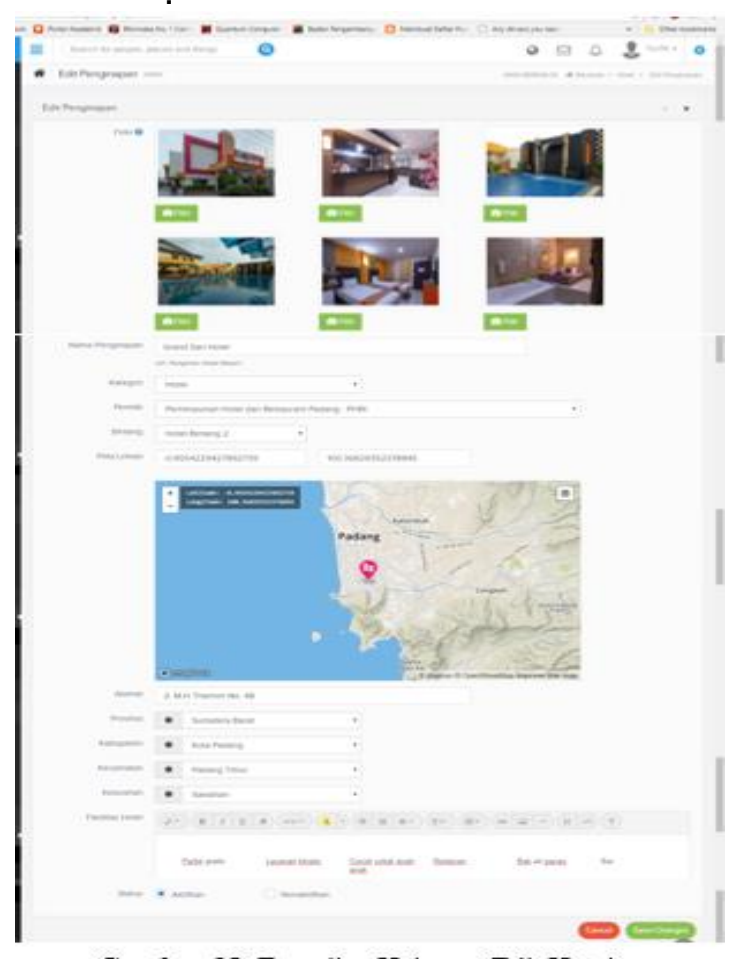

Gambar 28. Tampilan Halaman Edit Hotel 
4. Halaman Hapus Hotel Halaman hapus hotel merupakan konfirmasi untuk hapus hotel.

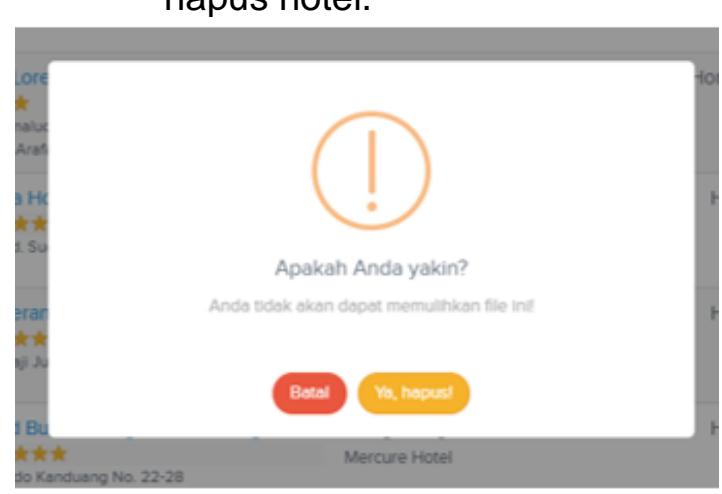

Gambar 29. Tampilan Hapus Hotel

5. Halaman Tambah Kamar Hotel

Halaman tambah kamar hotel merupakan halaman untuk melakukan penambahan kamar hotel ke dalam database. Tampilan halaman tambah kamar hotel dapat dilihat pada gambar berikut:

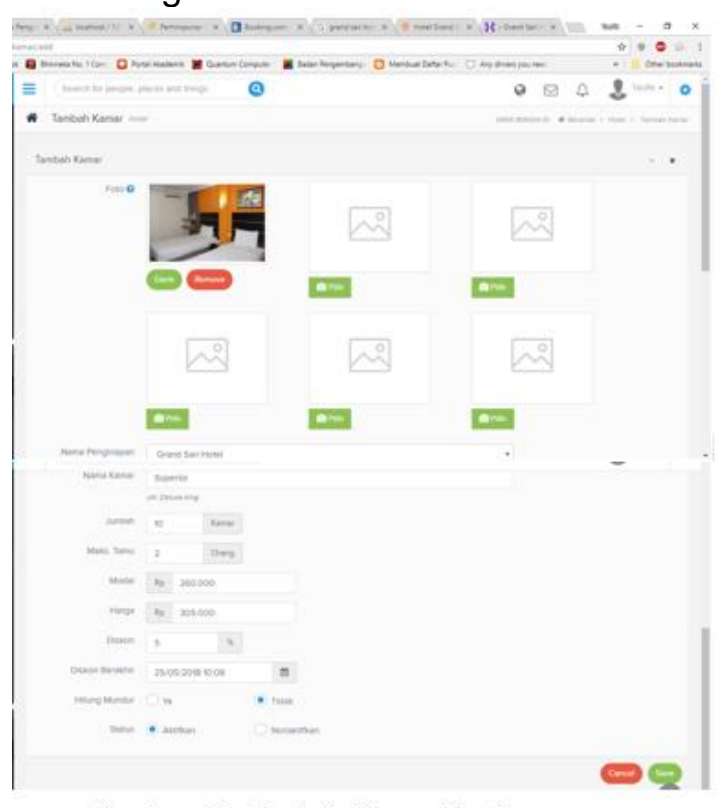

Gambar 30. Tambah Kamar Hotel

6. Halaman Edit Kamar Hotel Halaman edit kamar hotel digunakan untuk mengubah data kamar hotel yang sudah diinputkan.
Berikut adalah tampilan halaman edit kamar hotel:

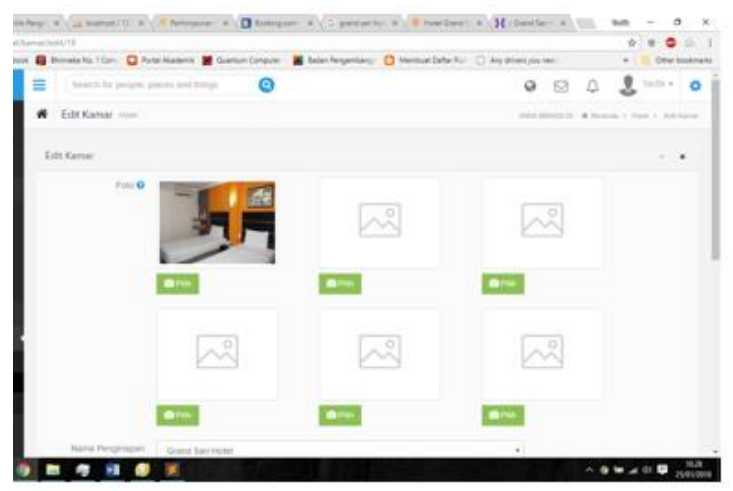

Gambar 31. Edit Kamar Hotel

\section{Halaman Data Booking}

Halaman data booking ini digunakan untuk melihat hasil hotel yang telah dibooking oleh pengguna.:

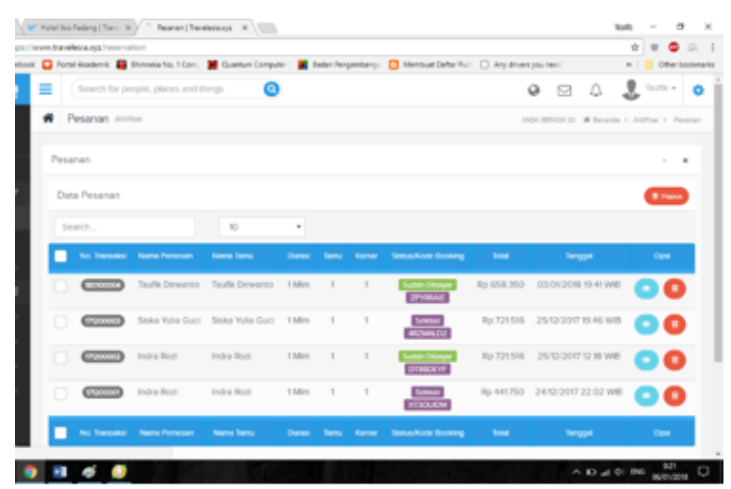

Gambar 32. Tampilan Halaman Data Booking

\section{Halaman Operator}

Halaman operator berfungsi untuk mengatur pesanan, data hotel, data kamar hotel, data tamu, booking, dan membuat promo.

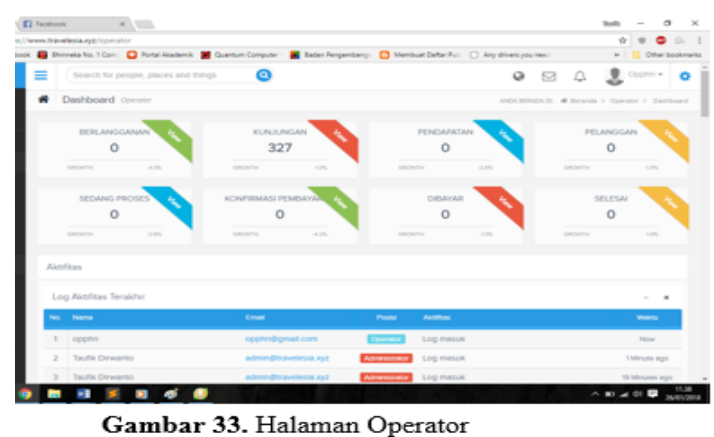

Gambar 33. Halaman Operator 


\section{Halaman Owner}

Halaman
digunakan owner
melihat data hotel yang
dimilikinya.

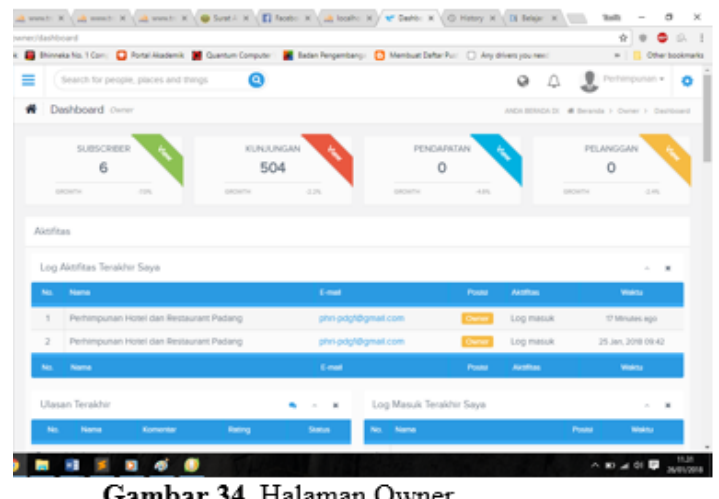

Gambar 34. Halaman Owner

10. Halaman Data Tamu

Halaman ini digunakan untuk melihat data tamu terdaftar.

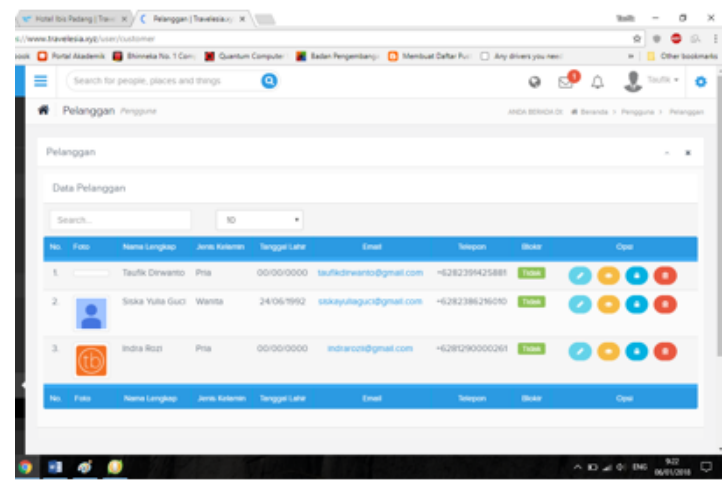

Gambar 35. Tampilan Halaman Data Tamu

Sistem informasi pengelolaan perhotelan di Kota Padang mempermudah pengelola untuk mengiklankan hotel maupun pencari hotel untuk mendapatkan informasi yang lengkap mengenai hotel yang tersedia. Aplikasi ini menampilkan hotel berdasarkan lokasi dengan petunjuk pointer pada peta digital Mapbox. Hotel yang ditampilkan hanyalah hotel yang masih memiliki kamar yang tersedia.

Perancangan sistem informasi ini menggunakan codeigniter sebagai framework. Ibnu

(2011:7) mengemukakan menggunakan framework "dengan

memanfaatkan design pattern MVC dan common function yang telah ada dalam framework maka hal tersebut dapat mempercepat proses pengembangan aplikasi". Kelebihan MVC terletak pada fungsi yang secara otomatis akan mengikuti struktur file yang ada di framework tersebut sehingga memudahkan manajemen source code.

\section{KESIMPULAN}

Berdasarkan

hasil

perancangan Sistem Informasi Pengelolaan Hotel di Kota Padang Menggunakan Mapbox Graphic Library, Berbasis Framework Codeigniter ini dapat disimpulkan sebagai berikut:

1. Dengan pemanfaatan bahasa pemograman menggunakan PHP Framework Codeigniter dapat dikembangkan sebuah sistem informasi pengelolaan hotel di Kota Padang menggunakan Mapbox Graphic Library berbasis web.

2. Dengan adanya sistem informasi ini dapat membantu user dalam pencarian hotel tanpa harus datang langsung ke hotel yang diinginkan.

3. Dengan adanya sistem informasi pengelolaan hotel dapat membantu untuk mempromosikan hotel yang tersedia di Kota.

Adapun saran yang diberikan setelah mengembangkan Sistem Informasi ini antara lain:

1. Pemberitahuan booking ke pemilik hotel masih melalui email, maka perlu dibuat pengembang sistem lebih lanjut dengan memberitahukan melalui SMS.

2. Pengembangan selanjutnya diharapkan menggunakan platform android sehingga bisa diakses lewat aplikasi mobile smartphone. 


\section{DAFTAR PUSTAKA}

[1] Abdul Kadir. 2014. Pengenalan Sistem Informasi Edisi Revisi. Yogyakarta: Andi.

[2] BPS Provinsi Sumatera Barat. 2015. Direktorat Hotel dan akomodasi lainnya Sumatera Barat. Padang: BPS Sumatera Barat.

[3] Ibnu Daqiqil

Id. (2011)."Framework

Codeigniter".

http://koder.web.id/bukucodeigniter-gratis/ (Diakses 11 Januari 2017)

[4] Ira Aprianis, Aditya Indra Lesmana. 2013. Sistem Informasi Manajemen Pada Hotel Gran Nikita Prabumulih

[6] Laudon, Kenneth C. 2014. Sistem Informasi Manajemen: Mengelola Perusahaan Digital. Jakarta: Salemba Empat

[7] Peraturan Menteri Pariwisata dan Ekonomi Kreatif No.53 Tahun 2013 tentang Standar Usaha Hotel. Jakarta: Menparekraf

[8] Rosa A. S \& M. Shalahuddin. 2013. Rekayasa Perangkat Lunak. Bandung: Informatika. 